\title{
Inhaled hydrogen sulfide protects against lipopolysaccharide-induced acute lung injury in mice
}

Simone Faller, , Kornelia K Zimmermann, Karl M Strosing, Helen Engelstaedter, Hartmut Buerkle, René Schmidt, Sashko G Spassov and Alexander Hoetzel

\begin{abstract}
Background: Local pulmonary and systemic infections can lead to acute lung injury (ALI). The resulting lung damage can evoke lung failure and multiple organ dysfunction associated with increased mortality. Hydrogen sulfide $\left(\mathrm{H}_{2} \mathrm{~S}\right)$ appears to represent a new therapeutic approach to ALI. The gas has been shown to mediate potent anti-inflammatory and organ protective effects in vivo. This study was designed to define its potentially protective role in sepsis-induced lung injury.

Methods: C57BL/6 N mice received lipopolysaccharide (LPS) intranasally in the absence or presence of 80 parts per million $\mathrm{H}_{2} \mathrm{~S}$. After $6 \mathrm{~h}$, acute lung injury was determined by comparative histology. Bronchoalveolar lavage (BAL) fluid was analyzed for total protein content and differential cell counting. BAL and serum were further analyzed for interleukin-1 $\beta$, macrophage inflammatory protein-2, and/or myeloperoxidase glycoprotein levels by enzyme-linked immunosorbent assays. Differences between groups were analyzed by one way analysis of variance.

Results: Histological analysis revealed that LPS instillation led to increased alveolar wall thickening, cellular infiltration, and to an elevated ALI score. In the presence of $\mathrm{H}_{2} \mathrm{~S}$ these changes were not observed despite LPS treatment. Moreover, neutrophil influx, and pro-inflammatory cytokine release were enhanced in BAL fluid of LPS-treated mice, but comparable to control levels in $\mathrm{H}_{2} \mathrm{~S}$ treated mice. In addition, myeloperoxidase levels were increased in serum after LPS challenge and this was prevented by $\mathrm{H}_{2} \mathrm{~S}$ inhalation.
\end{abstract}

Conclusion: Inhalation of hydrogen sulfide protects against LPS-induced acute lung injury by attenuating pro-inflammatory responses.

Keywords: Acute lung injury, Hydrogen sulfide, Sepsis, Lipopolysaccharide, Inflammation

\section{Background}

Acute lung injury (ALI), and the acute respiratory distress syndrome (ARDS), are two major challenges in clinical practice and both are responsible for high rates of morbidity and mortality amongst intensive care patients [1-3]. A variety of stimuli can initiate ALI, such as mechanical ventilation, hyperoxia, ischemia/reperfusion, transfusion, or polytrauma [3]. Sepsis reflects one of the most important causes of ALI [4]. The underlying strong inflammatory response in sepsis-induced ALI is characterized by the transmigration of immune-competent cells (mostly neutrophils)

\footnotetext{
* Correspondence: simone.faller@uniklinik-freiburg.de

Department of Anesthesiology and Critical Care Medicine, University Medical Center Freiburg, Hugstetter Str. 55, D-79106 Freiburg, Germany
}

into the lung interstitium and the alveolar space, and the release of numerous pro-inflammatory cytokines, e.g., interleukin-1 $\beta$ (IL-1 $\beta$ ) and macrophage inflammatory protein-2 (MIP-2). As a consequence of the inflammatory process, alveolar structures change, endothelial and alveolar permeability increase and alveolar fluid clearance decreases, thus critically impairing lung function [5]. Currently available treatment options have failed to significantly decrease sepsis related mortality. Therefore, alternative strategies are urgently needed to improve supportive care.

In this respect, hydrogen sulfide $\left(\mathrm{H}_{2} \mathrm{~S}\right)$ has come to be a focus of interest. $\mathrm{H}_{2} \mathrm{~S}$ belongs to the group of gaseous transmitters, along with nitric oxide and carbon monoxide. 
It is present in the blood and organs of humans and mammals in low micromolar extracellular concentrations. Endogenous $\mathrm{H}_{2} \mathrm{~S}$ has been shown to be involved in a series of physiological processes, e.g., inflammation, vasodilatation, neuromodulation, pain perception, as well as in organ protective pathways (reviewed in [6]). Moreover, exogenous application of gaseous $\mathrm{H}_{2} \mathrm{~S}$ and $\mathrm{H}_{2} \mathrm{~S}$ donors in different animal disease models like ventilator-induced lung injury [7], ischemia/reperfusion injury [8], or oleic acid-induced ALI [9,10], succeeded in exerting organprotective effects. The underlying mechanism may be explained by the ability of $\mathrm{H}_{2} \mathrm{~S}$ to inhibit the activation and transmigration of neutrophil cells and to attenuate the release of pro-inflammatory cytokines.

The aims of the present study were to mimic sepsisinduced ALI by intranasal administration of the endotoxin lipopolysaccharide (LPS) and to examine the role of continuously inhaled $\mathrm{H}_{2} \mathrm{~S}$ in this injury model.

\section{Methods}

\section{Animals and experimental setting}

All animal experiments were performed in accordance with the guidelines of the local animal care commission (Ethics Committee University of Freiburg, Freiburg, Germany, permission No. G-07/25) and in conformance with the journals' requirements for human and animal trials. C57BL/6 N mice weighing 22.4 g ( $\pm 0.3 \mathrm{~g}$ ) were randomly assigned into four experimental groups: (1) intranasal (i.n.) application of endotoxin-free phosphate buffered saline $(70 \mu \mathrm{l})+$ spontaneous breathing of room air (PBS + air), (2) PBS treatment + spontaneous breathing of air supplemented with 80 parts per million ( $\mathrm{ppm}$ ) hydrogen sulfide $\left(\mathrm{H}_{2} \mathrm{~S}\right.$, Air Liquide, Kornwestheim, Germany) $\left(\mathrm{PBS}+\mathrm{H}_{2} \mathrm{~S}\right)$, (3) i.n. application of lipopolysaccharide $(70 \mu \mathrm{l}$ dissolved in PBS, LPS; 0,25 ng E.coli 055:B5; Sigma-Aldrich Chemie $\mathrm{GmbH}$, Munich, Germany) + spontaneous breathing of air (LPS + air), (4) LPS treatment + spontaneous inhalation of 80 ppm $\mathrm{H}_{2} \mathrm{~S}$ ( $\mathrm{LPS}+\mathrm{H}_{2} \mathrm{~S}$ ). Spontaneous breathing of the respective gas mixture started $1 \mathrm{~h}$ prior to PBS or LPS instillation. Instillation of PBS or LPS was conducted under short isoflurane anesthesia. Afterwards, mice were again placed in a sealed plexiglass chamber and subjected to either breathe room air or $\mathrm{H}_{2} \mathrm{~S}$ for another $6 \mathrm{~h}$. $\mathrm{H}_{2} \mathrm{~S}$ concentration was continuously monitored using a portable gas monitor (MX6 iBrid, Industrial Scientific Corporation, Oakdale, PA).

\section{Tissue sampling and bronchoalveolar lavage}

At the end of each experiment all mice were sacrificed by an intraperitoneal, overdosed injection of ketamine $(180 \mathrm{mg} / \mathrm{kg})$ and acepromazine $(1.8 \mathrm{mg} / \mathrm{kg})$ and additional bleeding. Bronchoalveolar lavage fluid, lung tissue samples, and blood samples were gained and analyzed as described recently [11].

\section{Cytokine measurements}

BAL aliquots were analyzed using interleukin-1 $\beta$ (IL-1 $\beta$ ) and macrophage inflammatory protein-2 (MIP-2) ELISA kits (R\&D Systems GmbH, Wiesbaden, Germany) according to the manufacturers' instructions. Serum samples were tested using ELISA kits for myeloperoxidase (MPO) glycoprotein (HK210 ELISA, Hycult biotech GmbH, Beutelsbach, Germany) and IL-1 $\beta$ according to the manufacturers' instructions.

\section{Histological examination}

The left lung was prepared, conserved, and cut into $12 \mu \mathrm{m}$ thick cryosections for hematoxylin and eosin $(\mathrm{H}+\mathrm{E})$ staining as previously described [11]. From each lung, four representative photos were taken (magnification x200). Five high power fields (HPF) were randomly assigned to each photo. Subsequently, alveolar wall thickness and cellular infiltration were analyzed by Axiovision software (AxioVS40LE, Zeiss, Jena, Germany). For each HPF, the degree of lung damage was determined using a modified ALI score as described earlier [11]: In brief, (a) thickness of the alveolar walls, (b) infiltration or aggregation of inflammatory cells, and (c) hemorrhage were rated in a blinded fashion. Each item was graded according to the following point scale: 0 : minimal damage, 1 : mild damage, 2: moderate damage, 3: severe damage, 4: maximal damage. The degree of ALI was assessed by the sum of scores for each HPF, ranging from 0 to 12 . The average of the sum of each field score per lung was compared among groups.

\section{Statistical analysis}

Experiments were performed with 6-8 mice per group. Group size was defined on the basis of expected neutrophil cell numbers in BAL fluid by power calculations prior to the study. Graphs represent means \pm standard error of means (SEM). Data were further analyzed for normal variation prior to one way analysis of variance (ANOVA), followed by the Student-Newman-Keuls posthoc test. In cases of a failed normality test, Kruskal-Wallis ANOVA on Ranks was performed followed by Dunn`s posthoc test. $P<0.05$ was considered significant.

\section{Results and discussion}

In this study, we clearly demonstrate, that inhalation of $\mathrm{H}_{2} \mathrm{~S}$ in low dose prevents the development of acute lung injury. Furthermore, we show that $\mathrm{H}_{2} \mathrm{~S}$ treatment substantially reduces local as well as systemic inflammation.

\section{Hydrogen sulfide prevents lung damage in LPS-induced ALI}

In the presented model of pulmonary sepsis $\mathrm{H}+\mathrm{E}$ staining of lung cryosections showed that as compared to control conditions (PBS + air, $\mathrm{PBS}+\mathrm{H}_{2} \mathrm{~S}$, Figure $1 \mathrm{~A}+\mathrm{B}$, respectively), 


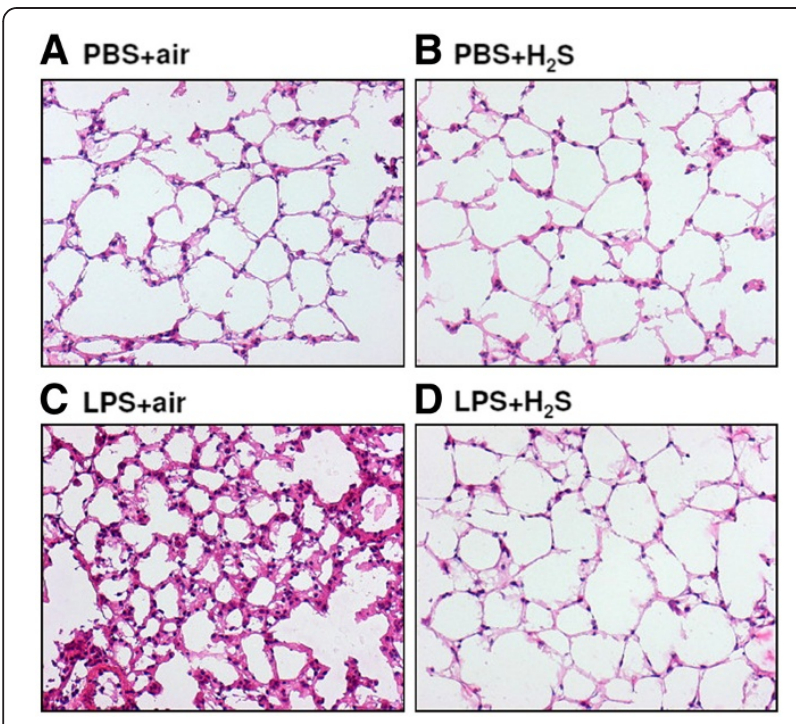

Figure 1 Effect of LPS and hydrogen sulfide inhalation on lung architecture. As controls, mice received phosphate buffered saline (PBS, intranasally) and were kept in room air (PBS + air, $\mathbf{A})$ or in 80 ppm $\mathrm{H}_{2} \mathrm{~S}\left(\mathrm{PBS}+\mathrm{H}_{2} \mathrm{~S}, \mathbf{B}\right)$ for $6 \mathrm{~h}$ (plus $1 \mathrm{~h}$ pretreatment). LPS-treated mice (LPS treatment, i.n.) were either kept in room air (LPS + air, C) or in 80 ppm $\mathrm{H}_{2} \mathrm{~S}\left(\mathrm{LPS}+\mathrm{H}_{2} \mathrm{~S}, \mathbf{D}\right)$ for $6 \mathrm{~h}$ (plus $1 \mathrm{~h}$ pretreatment). Sections from the left lung lobe were stained with hematoxylin and eosin. Representative pictures are shown for each experimental group (magnification $=200 \mathrm{X}$ ).

LPS treatment clearly stimulated the formation of lung edema and the influx of immune-competent cells (LPS + air, Figure 1C). In sharp contrast, exposure to $80 \mathrm{ppm}$ $\mathrm{H}_{2} \mathrm{~S}$ markedly reduced LPS-induced lung damage (LPS + $\mathrm{H}_{2} \mathrm{~S}$, Figure 1D), reflected by decreased edema formation and cellular infiltration into the lung tissue. These findings were confirmed by quantitative analysis: $\mathrm{H}_{2} \mathrm{~S}$ inhalation prevented alveolar wall thickening (Figure 2A) and cellular infiltration (Figure 2B), that was otherwise observed in LPS-treated animals kept in room air. In addition, a reduction of lung damage to control levels by $\mathrm{H}_{2} \mathrm{~S}$ inhalation was also detected by rating an overall ALI score (Figure 2C), strongly suggesting a lung-protective role for $\mathrm{H}_{2} \mathrm{~S}$ inhalation in LPS-induced ALI.

These results add important information to the role of exogenous $\mathrm{H}_{2} \mathrm{~S}$ in sepsis. Conflicting data exist in models of cecal ligation and puncture demonstrating aggravation [12-20] as well as substantial reduction of the resulting lung injury in response to application of $\mathrm{H}_{2} \mathrm{~S}$ donors $[21,22]$. It is likely that the route of administration, dosage, timing, and the purity of $\mathrm{H}_{2} \mathrm{~S}$ donors may be accountable for the inconsistent data. This study is the first to show that inhalation of $\mathrm{H}_{2} \mathrm{~S}$ clearly prevents lung damage due to local LPS-induced injury, underlining the therapeutic potential of this gas under septic conditions. Our findings are further supported by a recent publication by Tokuda et al. [23]. Here, in contrast to our study, LPS was applied systemically. The study found inhalation of $80 \mathrm{ppm} \mathrm{H}_{2} \mathrm{~S}$ substantially increased survival. Although the authors did not analyze histopathological changes in the lung, the data suggest an organ-protective effect of $\mathrm{H}_{2} \mathrm{~S}$ inhalation. Moreover, we have shown recently that inhalation of $\mathrm{H}_{2} \mathrm{~S}$ in low dosage $(80 \mathrm{ppm})$ ameliorated lung pathology in ventilator-induced lung injury [7]. In a related model, Francis et al. demonstrated, that inhalation of $60 \mathrm{ppm}$ was sufficient to exert a series of lung protective effects [24]. These data suggest that application of lower concentrations as we used can achieve lung protection. Although we did not detect any toxic side effects of $\mathrm{H}_{2} \mathrm{~S}$ inhalation in our model (data not shown), future studies in this direction are needed to minimize $\mathrm{H}_{2} \mathrm{~S}$ exposure.
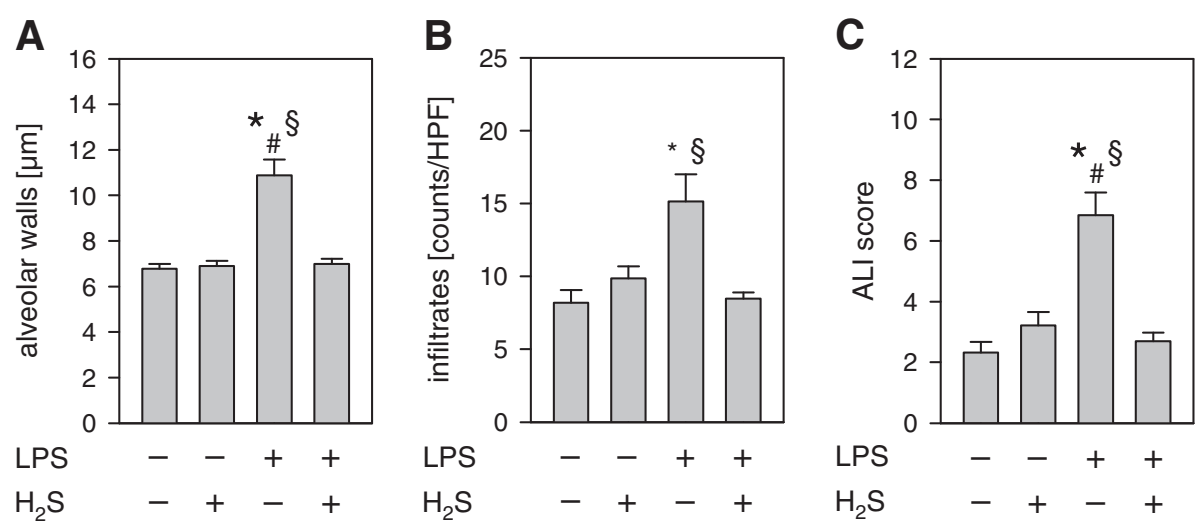

Figure 2 Effect of LPS and hydrogen sulfide inhalation on lung damage. As controls, mice received phosphate buffered saline (PBS, intranasally) and were kept in room air or in 80 ppm $\mathrm{H}_{2} \mathrm{~S}$ for $6 \mathrm{~h}$ (plus $1 \mathrm{~h}$ pretreatment). LPS-treated mice (LPS treatment, i.n.) were either kept in room air or in 80 ppm $\mathrm{H}_{2} \mathrm{~S}$ for $6 \mathrm{~h}$ (plus $1 \mathrm{~h}$ pretreatment). Sections from the left lung lobe were stained with hematoxylin and eosin. High power fields were randomly assigned to measure alveolar wall thickness (A), to count total infiltrate numbers (B), and to calculate an acute lung injury (ALI) score (C). Data represent means \pm SEM for $n=7-8 /$ group. ANOVA on Ranks (A + B, Dunn's posthoc test) and ANOVA (C; Student-Newman-Keuls posthoc test), ${ }^{*} P<0.05$ vs. PBS + air group; ${ }^{\#} P<0.05$ vs. $P B S+H_{2} S$ group; ${ }^{\circledR} P<0.05$ vs. LPS $+\mathrm{H}_{2} S$ group. 


\section{Hydrogen sulfide mediates lung protection by inhibition of the inflammatory response}

We next investigated whether the observed $\mathrm{H}_{2} \mathrm{~S}$-mediated lung-protection was attributed to inhibition of LPSinduced inflammation. The development of lung damage in pulmonary sepsis is known to be critically dependent on the initiation of an inflammatory response, mainly characterized by neutrophil transmigration and activation and pro-inflammatory cytokine release $[21,25]$. Neutrophil sequestration into the bronchoalveolar space was markedly increased by LPS application as compared to the control (Figure $3 \mathrm{~A}$ ). $\mathrm{H}_{2} \mathrm{~S}$ administration in LPS treated mice substantially reduced neutrophil numbers to control levels. Our data are in line with recent publications, where pulmonary neutrophil activity was found to be largely decreased in mice or rats, that had been protected from LPS-induced systemic inflammation both by inhaled $\mathrm{H}_{2} \mathrm{~S}$ [23] as well as by application of the slowly releasing $\mathrm{H}_{2} \mathrm{~S}$ donors S-diclofenac and GYY4137 [25,26]. The findings of these trials clearly support the notion that exogenous $\mathrm{H}_{2} \mathrm{~S}$ can inhibit pro-inflammatory processes. In combination with neutrophil transmigration, the release of proinflammatory cytokines, e.g., IL-1 $\beta$ and MIP-2, is known to aggravate lung injury $[21,25]$. In our study, quantitative analysis of IL- $1 \beta$ in the BAL revealed that it was nearly absent in both control groups (PBS + air and $\mathrm{PBS}+\mathrm{H}_{2} \mathrm{~S}$ ), whereas LPS instillation alone led to a vast increase of IL$1 \beta$ readings (Figure $3 \mathrm{~B}$ ). In sharp contrast, $\mathrm{H}_{2} \mathrm{~S}$ inhalation reduced IL-1 $\beta$ to control levels. Likewise, LPS treatment increased MIP-2 protein that was partially prevented by $\mathrm{H}_{2} \mathrm{~S}$ (Figure 3C). The attenuation of neutrophil transmigration and pro-inflammatory cytokine release by administration of $\mathrm{H}_{2} \mathrm{~S}$ has also been shown in other models of
ALI, e.g., ventilator-induced lung injury [7], oleic acidinduced lung injury $[9,10]$, caerulein-induced acute pancreatitis [27], or myocardial ischemia/reperfusion injury [28], strongly supporting our findings that gaseous $\mathrm{H}_{2} \mathrm{~S}$ substantially inhibits pulmonary inflammation and thereby limits LPS-induced lung damage. Future studies using different ALI models might discover the regulatory role of $\mathrm{H}_{2} \mathrm{~S}$ in each single aspect of human ALI / ARDS in order to define $\mathrm{H}_{2} \mathrm{~S}^{`}$ therapeutic potential.

We finally questioned whether intranasal application of LPS would also induce systemic inflammation and whether $\mathrm{H}_{2} \mathrm{~S}$ would exert any systemic effects. As a marker for neutrophil activity we determined the concentration of the MPO glycoprotein in serum [23,26]. In the present study, LPS treatment clearly increased serum MPO release. $\mathrm{H}_{2} \mathrm{~S}$ inhalation tended to reduce MPO levels, irrespective of the mode of additional PBS- or LPS-treatment (Figure 4A). Similar results were obtained by analyzing serum IL-1 $\beta$ levels (Figure 4B). Our findings compliment the results of two previous studies, where LPS-induced systemic inflammation (e.g., plasma nitrite/nitrate levels, proinflammatory cytokine release) was also clearly prevented by $\mathrm{H}_{2} \mathrm{~S}$ inhalation $[23,29]$. However, on the basis of our results, we cannot clearly decipher, whether i.n. LPS directly induced a systemic inflammation or whether the inflammatory response observed resulted from lung injury. Therefore two scenarios concerning the role of $\mathrm{H}_{2} \mathrm{~S}$ appear possible: (1) $\mathrm{H}_{2} \mathrm{~S}$ inhalation may directly inhibit lung and systemic inflammation, or (2) $\mathrm{H}_{2} \mathrm{~S}$ inhalation may primarily inhibit lung inflammatory responses, secondary preventing a systemic inflammation. Either way, our
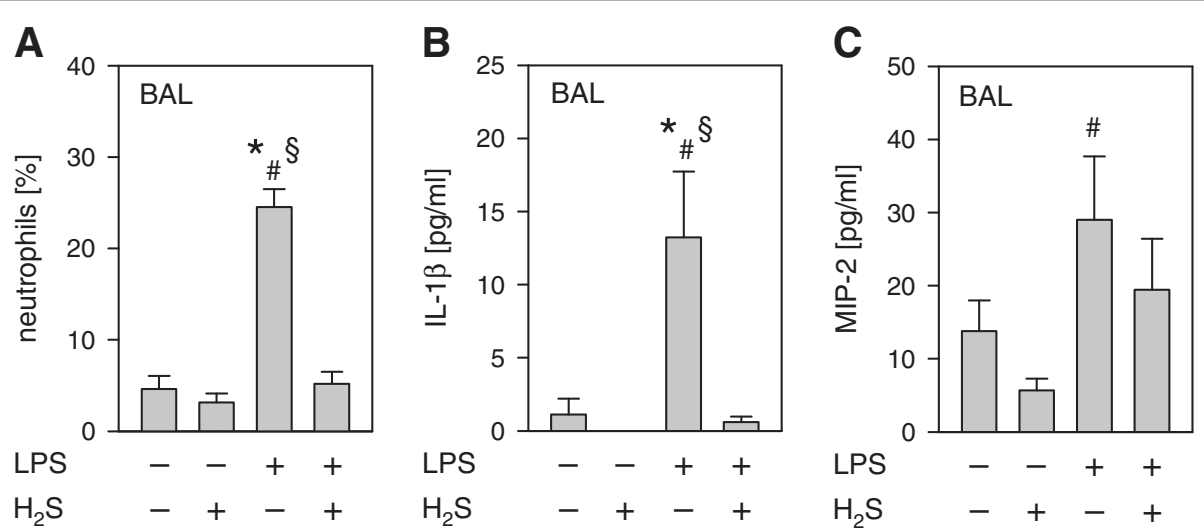

Figure 3 Effect of LPS and hydrogen sulfide inhalation on lung inflammation. As controls, mice received phosphate buffered saline (PBS,

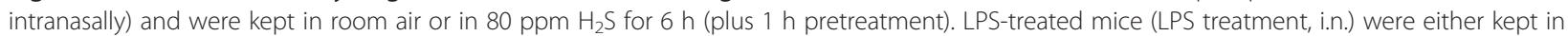
room air or in 80 ppm $\mathrm{H}_{2} \mathrm{~S}$ for $6 \mathrm{~h}$ (plus $1 \mathrm{~h}$ pretreatment). Bronchoalveolar lavage was performed in the right lung. The relative amount of neutrophils (A) was determined by cytospin analysis, and the amount of IL-1B (B) and MIP-2 (C) was determined by ELISA. Graphs represent means $\pm \mathrm{SEM}, n=8$ /group. ANOVA on Ranks (Dunn's posthoc test), ${ }^{*} P<0.05 \mathrm{Vs}$. $\mathrm{PBS}+$ air group; ${ }^{\#} P<0.05 \mathrm{Vs}$. PBS $+\mathrm{H}_{2} \mathrm{~S}$ group;

$\S_{P}<0.05$ vs. LPS $+\mathrm{H}_{2} \mathrm{~S}$ group. 


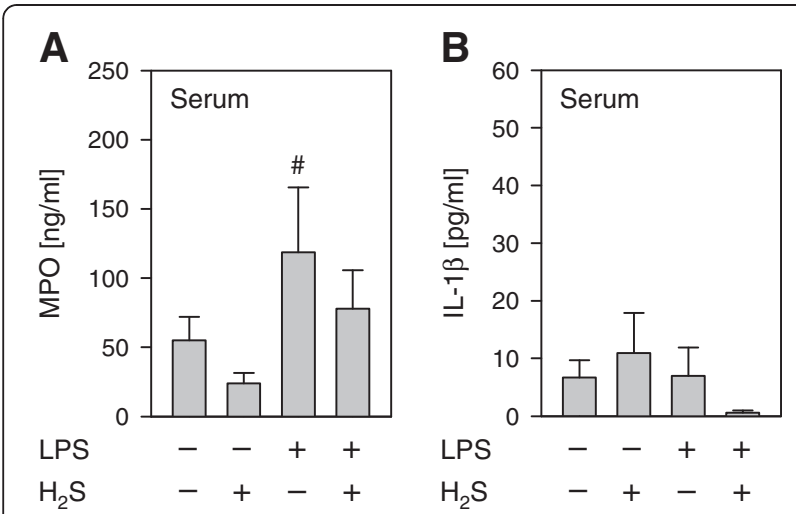

Figure 4 Effect of LPS and hydrogen sulfide inhalation on systemic inflammation. As controls, mice received phosphate buffered saline (PBS, intranasally) and were kept in room air or in

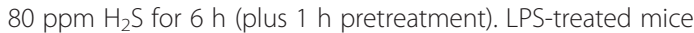
(LPS treatment, i.n.) were either kept in room air or in $80 \mathrm{ppm} \mathrm{H}_{2} \mathrm{~S}$ for $6 \mathrm{~h}$ (plus $1 \mathrm{~h}$ pretreatment). Blood samples were withdrawn by intracardiac punctation. Myeloperoxidase (MPO, A) and IL-1 $\beta$ (B) contents were quantified by ELISA in serum. Graphs represent means \pm SEM, $n=6-8 /$ group. ANOVA on Ranks (Dunn's posthoc test), ${ }^{\#} P<0.05$ vs. $\mathrm{PBS}+\mathrm{H}_{2} \mathrm{~S}$ group.

data suggest that $\mathrm{H}_{2} \mathrm{~S}$ inhalation has the potential to inhibit both local as well as systemic inflammatory responses to septic insults.

\section{Conclusions}

In our model, inhalation of hydrogen sulfide substantially reduced LPS-induced acute lung injury. The observed protection appears to be mediated by the anti-inflammatory effects of $\mathrm{H}_{2} \mathrm{~S}$, i.e., inhibition of neutrophil transmigration and pro-inflammatory cytokine release. Therefore, $\mathrm{H}_{2} \mathrm{~S}$ application displays organ protective properties.

\section{Competing interests}

The authors declare that they have no competing interests.

\section{Authors` contributions}

SF conducted the study and wrote the manuscript; KKZ helped to conduct the study and analyzed the data; KMS helped to conduct the study; HE helped to analyze the data and critically revised the manuscript; RS helped to design and conduct the study and to analyze the data; HB helped to analyze the data and to write the manuscript; SGS helped to conduct the study; AH designed and conducted the study, analyzed the data and wrote the manuscript. All authors read and approved the final manuscript.

\section{Acknowledgment}

This study was supported by a grant from the German Research Foundation (DFG, Bonn, Germany) to Alexander Hoetzel (DFG HO 2464/3-1).

Received: 24 September 2012 Accepted: 24 September 2012 Published: 1 October 2012

\section{References}

1. Rubenfeld GD, Caldwell E, Peabody E, Weaver J, Martin DP, Neff M, Stern EJ, Hudson LD: Incidence and outcomes of acute lung injury. N Engl J Med 2005, 353:1685-1693.

2. Tsushima K, King LS, Aggarwal NR, De Gorordo A, D'Alessio FR, Kubo K: Acute lung injury review. Intern Med 2009, 48:621-630.
3. Wheeler AP, Bernard GR: Acute lung injury and the acute respiratory distress syndrome: a clinical review. Lancet 2007, 369:1553-1564.

4. Martin GS, Mannino DM, Eaton S, Moss M: The epidemiology of sepsis in the United States from 1979 through 2000. N Engl J Med 2003, 348:1546-1554.

5. Matute-Bello G, Frevert CW, Martin TR: Animal models of acute lung injury. Am J Physiol Lung Cell Mol Physiol 2008, 295:L379-L399.

6. Whiteman M, Le Trionnaire S, Chopra M, Fox B, Whatmore J: Emerging role of hydrogen sulfide in health and disease: critical appraisal of biomarkers and pharmacological tools. Clin Sci (Lond) 2011, 121:459-488.

7. Faller S, Ryter SW, Choi AM, Loop T, Schmidt R, Hoetzel A: Inhaled hydrogen sulfide protects against ventilator-induced lung injury. Anesthesiology 2010, 113:104-115.

8. Biermann J, Lagreze WA, Schallner N, Schwer Cl, Goebel U: Inhalative preconditioning with hydrogen sulfide attenuated apoptosis after retinal ischemia/reperfusion injury. Mol Vis 2011, 17:1275-1286.

9. Li T, Zhao B, Wang C, Wang H, Liu Z, Li W, Jin H, Tang C, Du J: Regulatory effects of hydrogen sulfide on IL-6, IL-8 and IL-10 levels in the plasma and pulmonary tissue of rats with acute lung injury. Exp Biol Med (Maywood) 2008, 233:1081-1087.

10. Wang C, Wang HY, Liu ZW, Fu Y, Zhao B: Effect of endogenous hydrogen sulfide on oxidative stress in oleic acid-induced acute lung injury in rats. Chin Med J (Engl) 2011, 124:3476-3480.

11. Faller S, Foeckler M, Strosing KM, Spassov S, Ryter SW, Buerkle H, Loop T, Schmidt R, Hoetzel A: Kinetic effects of carbon monoxide inhalation on tissue protection in ventilator-induced lung injury. Lab Invest 2012, 92(7):999-1012.

12. Ang SF, Moochhala SM, Bhatia M: Hydrogen sulfide promotes transient receptor potential vanilloid 1-mediated neurogenic inflammation in polymicrobial sepsis. Crit Care Med 2010, 38:619-628.

13. Ang SF, Sio SW, Moochhala SM, MacAry PA, Bhatia M: Hydrogen sulfide upregulates cyclooxygenase-2 and prostaglandin E metabolite in sepsisevoked acute lung injury via transient receptor potential vanilloid type 1 channel activation. J Immunol 2011, 187:4778-4787.

14. Ang SF, Moochhala SM, MacAry PA, Bhatia M: Hydrogen sulfide and neurogenic inflammation in polymicrobial sepsis: involvement of substance P and ERK-NF-kappaB signaling. PLOS One 2011, 6:e24535.

15. Li L, Bhatia M, Zhu YZ, Zhu YC, Ramnath RD, Wang ZJ, Anuar FB, Whiteman M, Salto-Tellez M, Moore PK: Hydrogen sulfide is a novel mediator of lipopolysaccharide-induced inflammation in the mouse. FASEB $J$ 2005, 19:1 196-1198.

16. Zhang H, Zhi L, Moore PK, Bhatia M: Role of hydrogen sulfide in cecal ligation and puncture-induced sepsis in the mouse. Am J Physiol Lung Cell Mol Physiol 2006, 290:L1193-L1201.

17. Zhang H, Zhi L, Moochhala S, Moore PK, Bhatia M: Hydrogen sulfide acts as an inflammatory mediator in cecal ligation and puncture-induced sepsis in mice by upregulating the production of cytokines and chemokines via NF-kappaB. Am J Physiol Lung Cell Mol Physiol 2007, 292:L960-L971.

18. Zhang H, Hegde A, Ng SW, Adhikari S, Moochhala SM, Bhatia M: Hydrogen sulfide up-regulates substance $\mathrm{P}$ in polymicrobial sepsis-associated lung injury. J Immunol 2007, 179:4153-4160.

19. Zhang H, Zhi L, Moochhala SM, Moore PK, Bhatia M: Endogenous hydrogen sulfide regulates leukocyte trafficking in cecal ligation and puncture-induced sepsis. J Leukoc Biol 2007, 82:894-905.

20. Zhang H, Moochhala SM, Bhatia M: Endogenous hydrogen sulfide regulates inflammatory response by activating the ERK pathway in polymicrobial sepsis. J Immunol 2008, 181:4320-4331.

21. Huang XL, Zhou XH, Zhou JL, Ding CH, Xian XH: [Role of polymorphonuclear neutrophil in exogenous hydrogen sulfide attenuating endotoxin-induced acute lung injury.]. Sheng Li Xue Bao 2009, 61:356-360.

22. Spiller F, Orrico MI, Nascimento DC, Czaikoski PG, Souto FO, Alves-Filho JC, Freitas A, Carlos D, Montenegro MF, Neto AF, et al: Hydrogen sulfide improves neutrophil migration and survival in sepsis via K + ATP channel activation. Am J Respir Crit Care Med 2010, 182:360-368.

23. Tokuda K, Kida K, Marutani E, Crimi E, Bougaki M, Khatri A, Kimura H, Ichinose F: Inhaled hydrogen sulfide prevents endotoxin-induced systemic inflammation and improves survival by altering sulfide metabolism in mice. Antioxid Redox Signal 2012, 17:11-21. 
24. Francis RC, Vaporidi K, Bloch KD, Ichinose F, Zapol WM: Protective and Detrimental Effects of Sodium Sulfide and Hydrogen Sulfide in Murine Ventilator-induced Lung Injury. Anesthesiology 2011, 115:1012-1021.

25. Li L, Rossoni G, Sparatore A, Lee LC, Del Soldato P, Moore PK: Antiinflammatory and gastrointestinal effects of a novel diclofenac derivative. Free Radic Biol Med 2007, 42:706-719.

26. Li L, Salto-Tellez M, Tan CH, Whiteman M, Moore PK: GYY4137, a novel hydrogen sulfide-releasing molecule, protects against endotoxic shock in the rat. Free Radic Biol Med 2009, 47:103-113.

27. Sidhapuriwala JN, Ng SW, Bhatia M: Effects of hydrogen sulfide on inflammation in caerulein-induced acute pancreatitis. J Inflamm (Lond) 2009, 6:35.

28. Sodha NR, Clements RT, Feng J, Liu Y, Bianchi C, Horvath EM, Szabo C, Stahl GL, Sellke FW: Hydrogen sulfide therapy attenuates the inflammatory response in a porcine model of myocardial ischemia/reperfusion injury. $J$ Thorac Cardiovasc Surg 2009, 138:977-984.

29. Wagner F, Wagner K, Weber S, Stahl B, Knoferl MW, Huber-Lang M, Seitz DH Asfar P, Calzia E, Senftleben U, et al: Inflammatory effects of hypothermia and inhaled $\mathrm{H} 2 \mathrm{~S}$ during resuscitated, hyperdynamic murine septic shock. Shock 2011, 35:396-402.

doi:10.1186/2045-9912-2-26

Cite this article as: Faller et al:: Inhaled hydrogen sulfide protects against lipopolysaccharide-induced acute lung injury in mice. Medical Gas Research 2012 2:26.

\section{Submit your next manuscript to BioMed Central and take full advantage of:}

- Convenient online submission

- Thorough peer review

- No space constraints or color figure charges

- Immediate publication on acceptance

- Inclusion in PubMed, CAS, Scopus and Google Scholar

- Research which is freely available for redistribution 